\title{
Study Protocol Version Primary Purpose Code
}

National Cancer Institute

\section{Source}

National Cancer Institute. Study Protocol Version Primary Purpose Code. NCI Thesaurus.

Code C94121.

A coded value specifying the type of study based upon the intent of the study's activities. 